\title{
Application of molecular typing methods to dermatophyte species that cause skin and nail infections
}

\author{
S. A. HOWELL, R. J. BARNARD* and F. HUMPHREYS ${ }^{\dagger}$ \\ Department of Microbial Diseases, St John's Institute of Dermatology, St Thomas' Hospital, UMDS, London \\ SE $17 E H,{ }^{*}$ Department of Microbiology, Queen Elizabeth Hospital, King's Lynn, Norfolk PE30 4ET and \\ †Department of Dermatology, Royal Infirmary, Edinburgh EH3 $9 \mathrm{YW}$
}

\begin{abstract}
Typing methods utilising DNA technology were applied to a collection of Trichophyton mentagrophytes and $T$. rubrum isolates from skin and nail infections. The methods included restriction enzyme analysis (REA), hybridisation with the DNA probe poly (dGdT), randomly amplified polymorphic DNA (RAPD) by PCR and restriction analysis of a segment of PCR-amplified rDNA. All these tests successfully differentiated the species, but few intra-species differences were detected. REA demonstrated some isolate variation, but this was limited and difficult to interpret, making it unsuitable as a typing tool. RAPD demonstrated few variations amongst $T$. mentagrophytes and none in T. rubrum.
\end{abstract}

\section{Introduction}

Dermatophytes are capable of infecting nails and the skin from almost any body site. One of the frequently encountered dermatophyte infections is athlete's foot or tinea pedis. This can be a recurring infection and is most often caused by the dermatophyte species Trichophyton rubrum and T. mentagrophytes. When infection recurs it is not possible to establish if this is due to relapse from a previous infection or due to a newly acquired organism, as there are no typing techniques available to differentiate strains of these species. Furthermore, the ability to identify individual organisms would enable sources of infection to be identified, such as communal swimming and washing facilities, and appropriate control measures applied.

Dermatophyte species are well defined by morphological methods, but there have been relatively few attempts to devise typing techniques that would enable epidemiological studies to be performed. Some studies of cellular proteins by polyacrylamide gel electrophoresis have shown subspecies differences [1], but this has not been a universal finding [2]. There have been few reports of the application of molecular DNA

Received 28 April 1997; revised version accepted 17 April 1998.

Corresponding author: Dr S. A. Howell. techniques for the study of dermatophytes. The $\mathrm{G}+\mathrm{C}$ composition was in the narrow range of 48.7$50.3 \mathrm{~mol} \%$ for species of the three dermatophyte genera [3], and the DNA homology of T. rubrum and T. mentagrophytes to Arthroderma benhamiae, one of the teleomorph species, was shown to be in the range $71-76 \%$ [4], indicating a closely related group of fungi. Other reports have compared the mitochondrial DNA composition by restriction enzyme analysis (REA) and found the $T$. mentagrophytes var. interdigitale isolates to be highly uniform in content and indistinguishable from $A$. vanbreuseghemii, its teleomorphic species $[5,6]$. T. rubrum was reported to contain two types of mitochondrial DNA patterns, one of which was phylogenetically grouped with isolates of T. mentagrophytes, T. mentagrophytes var interdigitale, T. mentagrophytes var goetzii, T. tonsurans and $A$. vanbreuseghemii [7].

Typing methods applied to bacterial and yeast epidemiology include REA, hybridisation with DNA probes, polymerase chain reaction (PCR) and random amplification of polymorphic DNA (RAPD). We and others have achieved success with many of these methods in studies of Candida albicans [8-11] and Malassezia spp. [12,13], and recently there have been reports of typing Aspergillus spp. by RAPD and REA [14]. Therefore, these techniques were used to examine the differentiation of dermatophyte strains and species from skin and nail infections. 


\section{Materials and methods}

\section{Strains}

The isolates described in this study were kindly identified and provided by Dr Y. Clayton of St John's Institute of Dermatology, London, Dr J. Reuter of the William Harvey Hospital, Ashford, Kent, Mr R. J. Barnard of the Queen Elizabeth Hospital, King's Lynn and Dr Humphreys of the Royal Infirmary, Edinburgh. The reported sites of isolation of these dermatophytes were given as follows: $30 \mathrm{~T}$. mentagrophytes and $24 \mathrm{~T}$. rubrum from skin or nail of the feet; seven $T$. mentagrophytes and three T. rubrum from nail; one $T$. mentagrophytes from fingernail; one $T$. rubrum from the shoulder; one T. rubrum from the leg and one $T$. mentagrophytes from the skin of the scalp.

\section{Growth}

Dermatophyte isolates were grown on Oxoid Sabouraud Dextrose Agar (Unipath, Basingstoke) and spore suspensions were prepared and stored in distilled water at room temperature. Isolates were grown in $10 \mathrm{ml}$ of Sabouraud broth (Oxoid Mycopeptone $10 \mathrm{~g} / \mathrm{L}$, dextrose $40 \mathrm{~g} / \mathrm{L}$ ) in a $28-\mathrm{ml}$ screw-capped bottle at $30^{\circ} \mathrm{C}$ in an orbital incubator for 3-4 days. The fungus culture was then vortex mixed with sterile glass beads to produce short mycelial fragments and this suspension was used to inoculate $100 \mathrm{ml}$ of Sabouraud broth which was cultured with shaking overnight.

\section{DNA extraction}

The mycelial mass was harvested by centrifugation, washed with sterile distilled water and resuspended in $10 \mathrm{ml}$ of SCS buffer (1 M sorbitol, $20 \mathrm{mM}$ sodium citrate; Sigma); $200 \mu \mathrm{l}$ of a solution containing zymolyase $20 \mathrm{~T}$ (ICN Biomedicals) $3 \mathrm{mg}$ and novozyme (Calbiochem) $3 \mathrm{mg}$ was added followed by $\beta$-mercaptoethanol (Sigma) $175 \mu \mathrm{l}$, and the suspension was incubated at $30^{\circ} \mathrm{C}$ for $5 \mathrm{~h}$. The mycelial mass was pelleted by centrifugation at $2000 \mathrm{~g}$, suspended in $2 \mathrm{ml}$ of GES reagent $(5 \mathrm{M}$ guanidium thiocyanate, $100 \mathrm{mM}$ EDTA, lauroylsarcosine 0.5\%) [15] and kept at room temperature for $30 \mathrm{~min}$. After the addition of cold $5 \mathrm{M}$ potassium acetate (Sigma) $400 \mu \mathrm{l}$ and incubation for $30 \mathrm{~min}$ on ice, chloroform:pentanol (24:1; Sigma) $2 \mathrm{ml}$ was added, mixed and then centrifuged at $2000 \mathrm{~g}$ for 5 min. The upper aqueous phase was removed and DNA was precipitated with an equal volume of cold absolute ethanol and placed at $-20^{\circ} \mathrm{C}$ overnight. The DNA was pelleted by centrifugation at $4000 \mathrm{~g}$ for $10 \mathrm{~min}$, dissolved in $0.75 \mathrm{ml}$ TE buffer $(10 \mathrm{mM}$ Tris, $1 \mathrm{mM}$ EDTA, $\mathrm{pH} 8$ ) and $20 \mu \mathrm{l}$ of RNAase $5 \mathrm{mg} / \mathrm{ml}$ were added and allowed to digest for $2 \mathrm{~h}$ at $37^{\circ} \mathrm{C}$. The DNA solution was then purified by phenol-chloroform extraction and the DNA was precipitated with ethanol. Finally, after centrifugation at $10000 \mathrm{~g}$ for $5 \mathrm{~min}$ the DNA pellet was dissolved in $50 \mu 1$ of $\mathrm{TE}$.

\section{Restriction endonuclease analysis}

DNA solution $(25 \mu \mathrm{l})$ incubated at $37^{\circ} \mathrm{C}$ for $4 \mathrm{~h}$ with $10-15 \mathrm{U}$ of restriction endonuclease in the buffer concentration recommended by the manufacturer. The endonucleases used were $A c c$ I, Bam HI, Bgl II, Cla I, Eco RI, Hae III, Hinc II, Hind III, Hinf I, Hpa II, Pst I, $P v u \mathrm{II}, X b a \mathrm{I}$ or Xho I (Pharmacia, Herts, or BRL, Paisley). The DNA fragments were separated by electrophoresis in agarose $0.8 \%$ gels, submerged in TBE buffer ( $89 \mathrm{mM}$ Trizma, $32 \mathrm{mM}$ boric acid, $2.5 \mathrm{mM}$ EDTA; Sigma), at $30 \mathrm{~V}$ for $16 \mathrm{~h}$. The gels were stained with ethidium bromide and recorded on Polaroid 665 film or on a UV Product (Cambridge) video camera system.

\section{Hybridisation with poly (dG-dT)}

Restriction gels were Southern blotted [16] on to Stratagene (Cambridge) flash prime nylon membrane. Poly (dG-dT) (Pharmacia) was biotinylated with the photobiotin labelling kit from BRL according to the manufacturer's instructions. The blots were pre-hybridised for $4 \mathrm{~h}$ at $42^{\circ} \mathrm{C}$ in formamide $50 \%, 5 \times \mathrm{SSC}$ $(1 \times \mathrm{SSC}$ is $150 \mathrm{mM} \mathrm{NaCl}, 15 \mathrm{~mm}$ sodium citrate, $\mathrm{pH}$ 7.0), $5 \times$ Denhardt's solution (USB, Amersham International, Bucks) and fat-free milk $5 \%$ solution (dried fat-free UHT milk powder suspended in water to $5 \%$ ). Hybridisation was performed at $42^{\circ} \mathrm{C}$ for $18 \mathrm{~h}$ in formamide $40 \%, 5 \times \mathrm{SSC}, 1 \times$ Denhardt's solution, fat-free milk $5 \%$ solution, dextran sulphate $5 \%$ and poly (dG-dT) at a concentration of approximately $100 \mathrm{ng} / \mathrm{ml}$.

The membranes were washed five times at room temperature in $2 \times \mathrm{SSC}$ and hybridisation was detected by the BRL streptavidin alkaline phosphatase, BluGENE detection system according to the manufacturer's instructions.

\section{$R A P D$}

Approximately $10 \mathrm{ng}$ of DNA was placed into a $0.5-\mathrm{ml}$ tube with a reaction mix containing $1 \times$ magnesiumfree reaction buffer (Promega, Hants), $2 \mathrm{mM} \mathrm{MgCl}_{2}$, $3 \mathrm{U}$ Taq polymerase (Promega), $0.1 \mathrm{~mm}$ deoxynucleotides (Sigma), $8-16 \mathrm{nM}$ primer made up to a total volume of $50 \mu \mathrm{l}$ with molecular biology grade water and overlaid with mineral oil (Sigma). Primers OPA 120 were obtained from Operon Technologies Products (Newcastle upon Tyne, Tyne and Wear) all with a $50 \mathrm{~mol} \% \mathrm{G}+\mathrm{C}$ content. Primers 515FPL 5'-GCCAGCAGCCGCGGTAA-3' [17], 806R 5'-GGACTACAGGGTATCTAAT-3' [18] and 1492RPL 5'-GGTTACCTTGTTACGACTT-3' [19] were a gift from Dr E. Power (St Thomas' Hospital, London), primers 213 5'TCGGTGGCTGCTGCCCCCACC-3' and 215 5'-GCGTACCCCGGCGACCTCACC-3' [20], primers ERIC 2 5'-AAGTAAGTGACTGGGGTGAGCG-3' and ERIC 
IR $5^{\prime}$-ATGTAAGCTCCTGGGGATTCAC-3' [13] and HLWL85 5'-ACAACTGCTC-3' [21] were made by Pharmacia.

The PCR reactions were performed in a Hybaid thermocycler with conditions of $1 \mathrm{~min}$ at $94^{\circ} \mathrm{C}, 2 \mathrm{~min}$ at $34^{\circ} \mathrm{C}, 2 \mathrm{~min}$ at $72^{\circ} \mathrm{C}$ for 30 cycles, or a Perkin Elmer model 480 thermal cycler with conditions of $45 \mathrm{~s}$ at $94^{\circ} \mathrm{C}, 45 \mathrm{~s}$ at $34^{\circ} \mathrm{C}, 1.5 \mathrm{~min}$ at $72^{\circ} \mathrm{C}$. The PCR products were separated on agarose $2 \%$ gels submerged in TBE at $70 \mathrm{~V}$ for $4 \mathrm{~h}$. The DNA was stained with ethidium bromide and recorded photographically.

\section{Amplification and restriction of the 5.8S rDNA and internal transcribed spacer regions}

Primers ITS1 $5^{\prime}$ TCCGTAGGTGAACCTGCGG $3^{\prime}$ and ITS4 5' TCCTCCGCTTATTGATATGC 3' [22] were used for amplification of dermatophyte rDNA. The reaction mix consisted of $1 \times$ magnesium-free reaction buffer, $1.5 \mathrm{mM} \mathrm{MgCl}_{2}, 0.2 \mathrm{mM}$ deoxynucleotides, $2 \mathrm{nM}$ of each primer (Pharmacia), $3 \mathrm{U}$ Taq polymerase and $c$. $10 \mathrm{ng}$ DNA, made up to a total volume of $50 \mu \mathrm{l}$ with molecular biology grade water and overlaid with mineral oil. This was placed into the Hybaid thermocycler for 30 cycles of $95^{\circ} \mathrm{C}$ for $1 \mathrm{~min}, 55^{\circ} \mathrm{C}$ for $30 \mathrm{~s}$, $72^{\circ} \mathrm{C}$ for $1 \mathrm{~min}$.

The rDNA fragments were digested with endonuclease by placing $6 \mu \mathrm{l}$ of the amplified DNA solution into a reaction tube and adding $0.5 \mu \mathrm{l}$ of $10 \times$ restriction enzyme buffer, $0.5 \mu \mathrm{l}$ restriction endonuclease and $4 \mu \mathrm{l}$ water. This was incubated at $37^{\circ} \mathrm{C}$ for $4 \mathrm{~h}$ and the fragments were separated in polyacrylamide $6 \%$ gels (acrylamide:bis-acrylamide ratio 29:1, Sigma), submerged in TBE at $6-7 \mathrm{~V} / \mathrm{cm}$. The gels were stained with ethidium bromide and photographed. The restriction endonucleases used were: Alu I, Eco RI, Hae III, Hinf I, Hpa II, Mbo I, Msp I, Rsa I and Taq I from Pharmacia or BRL.

\section{Results and discussion}

Restriction digests were difficult to interpret because of background genomic smearing and the large numbers of bands produced by many of the endonucleases. Patterns from $23 T$. mentagrophytes isolates were very similar with Eco RI, demonstrating minimal band variation in the $4-\mathrm{kb}$ region of the gel. Fig. $\mathrm{la}$ and $\mathrm{b}$ shows typical patterns from isolates of $T$. mentagrophytes and T. rubrum. Generally, it was more difficult to obtain interpretable RFLP patterns from $T$. rubrum and $E c o$ RI digests of 13 isolates showed minimal band variation in the $5-6 \mathrm{~kb}$ region (data not shown). The endonuclease of choice was Eco RI, although several other endonucleases produced some bright bands, including $X b a \mathrm{I}, X h o \mathrm{I}$ and Pst I. Hpa II, HinfI and $M b o$ I were not suitable, as they produced patterns in the 5-kb region and less. However, for a typing tool to be useful the results need to be clearly distinguishable and a number of different types must be recognised for the method to have wide applicability. Few differences in the REA patterns were detected, the results were often difficult to see and these factors combined with gel-to-gel variation made interpretation difficult. Therefore a DNA probe was selected to enhance the interpretation of the results and to provide better discrimination.

Poly (dG-dT) has been used successfully to differentiate strains of C. albicans [23], C. glabrata [24] and Malassezia pachydermatis [12] and appeared to be an ideal probe for the epidemiology of the dermatophytes. Hybridisation to blots of Eco RIdigested DNA demonstrated minimal variation in 28 isolates of T. mentagrophytes around $9 \mathrm{~kb}$, and in 12 isolates of $T$. rubrum between 3 and $4 \mathrm{~kb}$ (Fig. 2). On this basis, only two or three types of each species could be detected. The choice of restriction endonuclease can affect the discrimination of strains $[12,24,25]$ and hence the discrimination of the probe. Therefore the panel of restriction endonucleases was used to digest DNA from three isolates of each species and the blots of these gels were probed with poly (dG-dT). As so few variations between isolates had been detected by $E c o$ RI, and to prevent the possibility of comparing a common type with each enzyme, at least one of the isolates was varied in each digest. All the endonucleases tested produced almost identical poly (dG-dT) patterns for isolates of T. mentagrophytes (Figs 2 and 3 ) and of T. rubrum (Figs 2 and 4), and although minor differences of one band were seen these would not be sufficient for the discrimination of large numbers of isolates. Micro-organisms have been shown to exhibit restriction fragment length polymorphisms due to point mutations [25], and the C. albicans-specific $27 \mathrm{~A}$ probe has been shown to give small differences in the patterns of the same isolate after several subcultures [26]. Therefore, the small differences described from the dermatophyte typing by REA and poly (dG-dT) would be of doubtful significance for epidemiological purposes.

One of the newest techniques for large-scale strain differentiation is RAPD. After selection of a primer that confers the best discrimination, RAPD has been shown to differentiate strains of $C$. albicans, Aspergillus fumigatus and several bacterial species $[8,10$, $14,27,28]$. A total of 26 primers was tested for the discrimination of up to eight isolates of T. rubrum and eight of $T$. mentagrophytes. The majority of primers tested were 10-mers with GC contents of $50 \mathrm{~mol} \%$; however, other primers of 17-21-mer lengths and with GC contents of $42-76 \mathrm{~mol} \%$ were tried. All the primers enabled the two species to be recognised, but none could distinguish between the isolates of $T$. rubrum. From the eight $T$. mentagrophytes isolates 


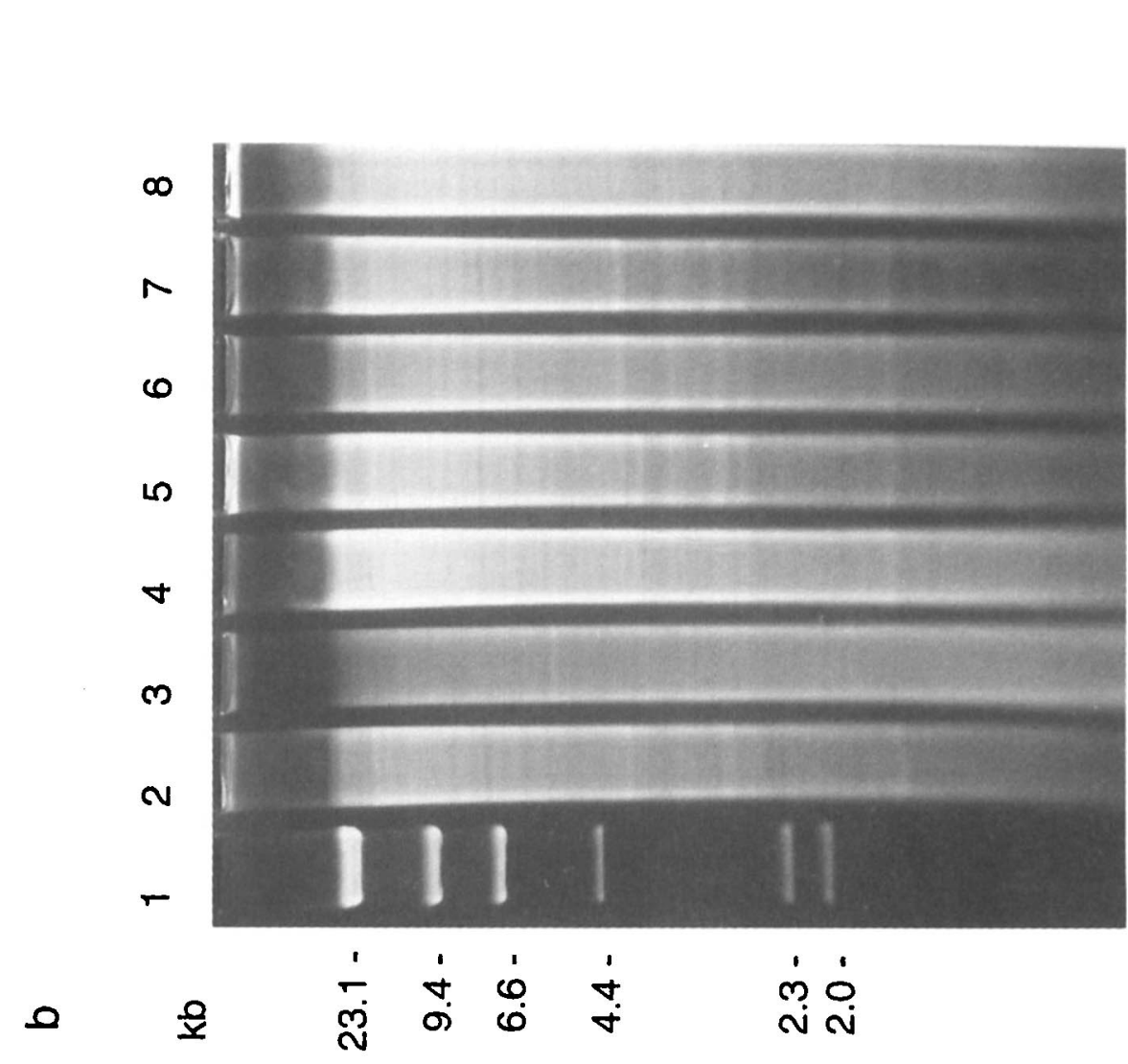

$\Xi$

。ำ

藏

$\exists \infty$

$\Xi \underset{\sigma}{0}$

in

ลัต

$\overline{1}$

$\mapsto \dot{y}$

证

吾旦

$\Xi \ddot{\circ}$

m.

过寻恋

$E$ in

in

质家

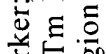

范

$\exists \ddot{\sim} \ddot{y}$

弯当

踏 $r+\frac{10}{20}$ $\stackrel{\infty}{\bar{\sigma}}$ 西。
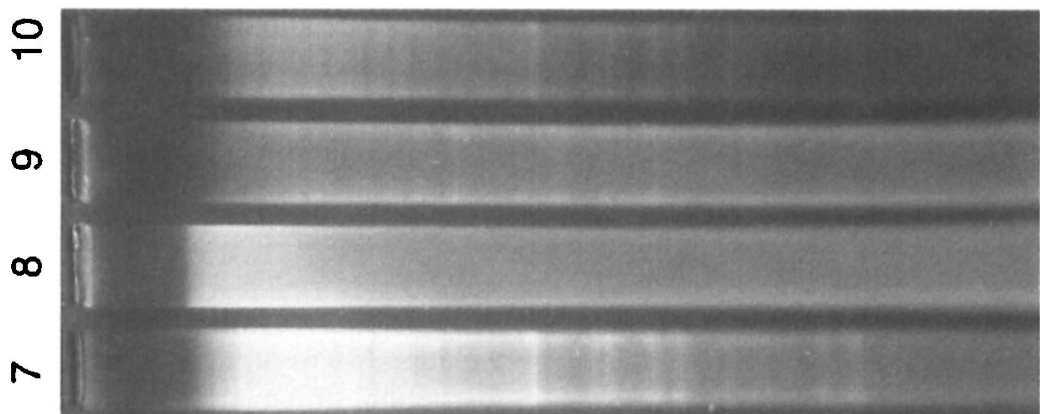
बछ 它的 홓츨 害

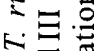
콘 \% 国节 政 要 호을 so․ 密它

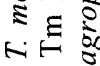
¿응 4 찬 웅조 EF 实 的? 艺龒 王

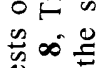

ఠ

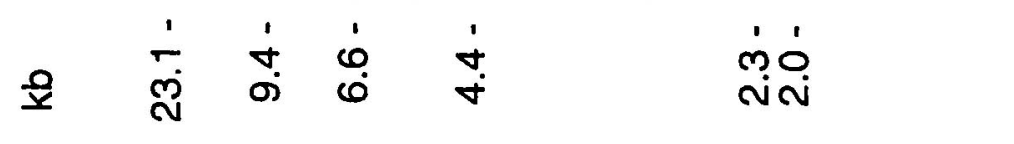

.0

$\bar{x} \frac{8}{5}$ 코 됴용 ำํํำ 


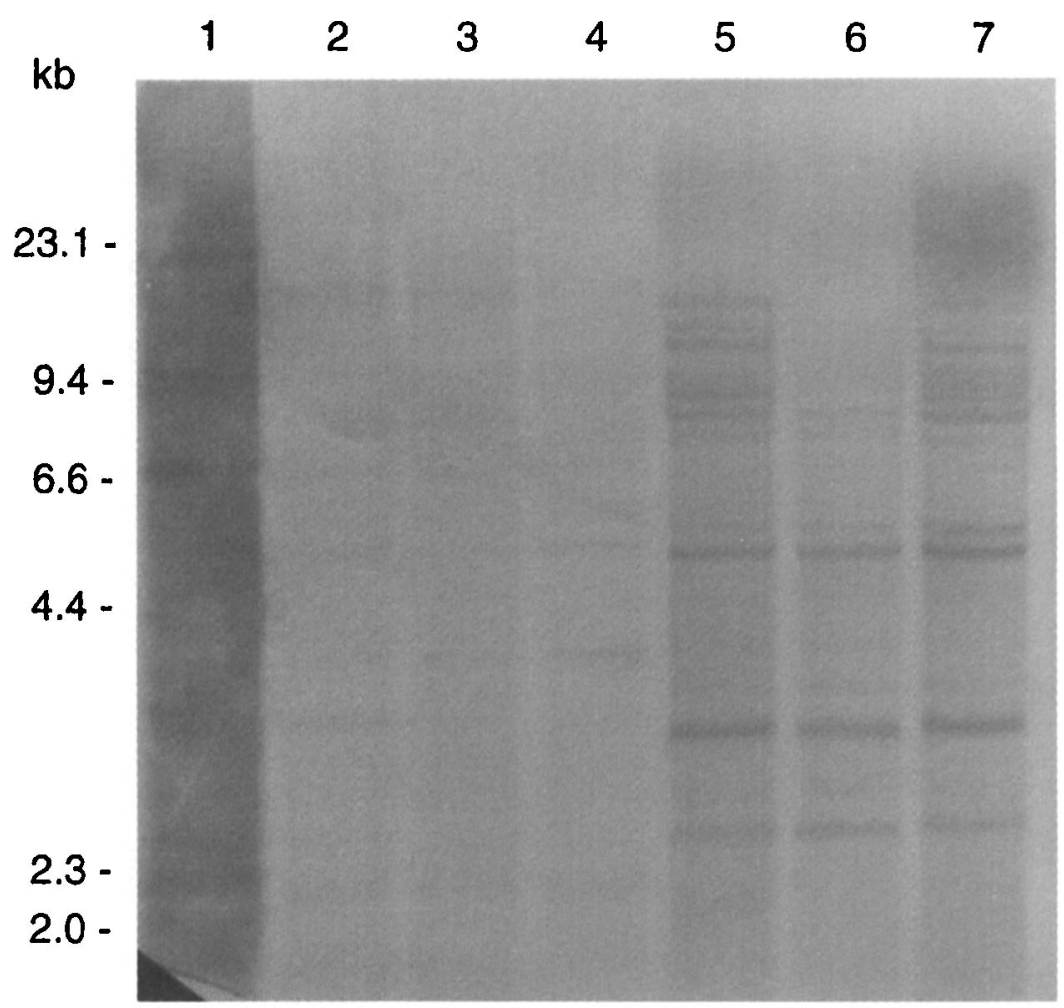

Fig. 2. Poly (dG-dT) blot of Eco Rl-digested DNA from isolates of T. mentagrophytes and T. rubrum demonstrating species differences, but only minor strain differences. Lane 1, $\lambda$ Hind III; 2, Tr 035; 3, Tr H391; 4, Tr 011; 5, Tm 138; 6, Tm 349; 7, Tm 439.

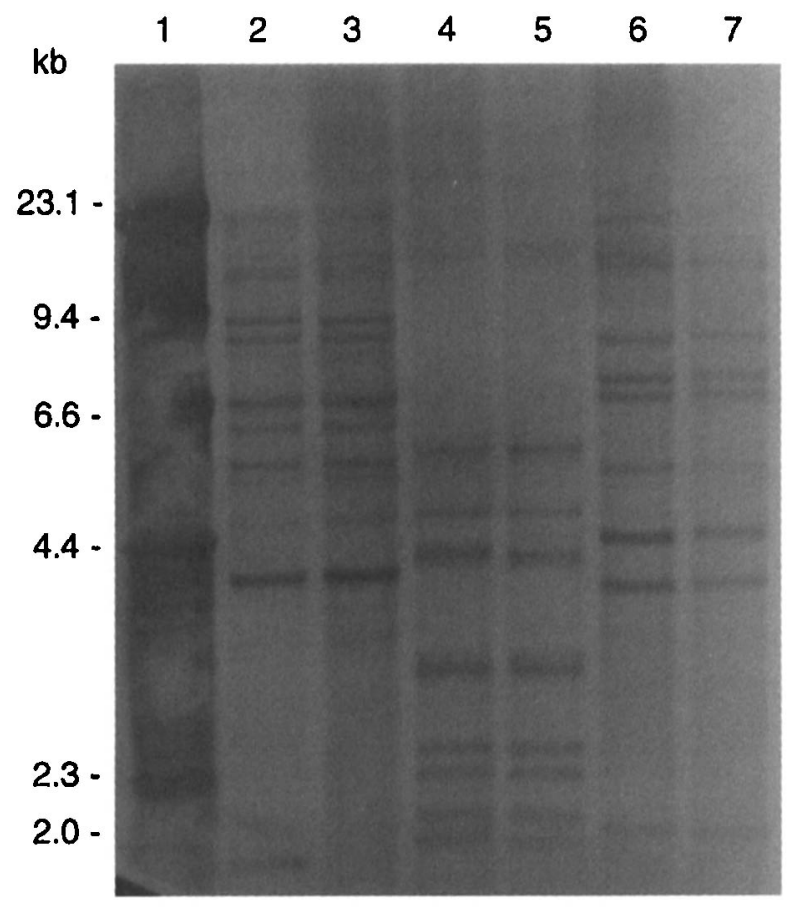

Fig. 3. Poly (dG-dT) blots of $T$. mentagrophytes DNA digested with $X b a \mathrm{I}$, Pst I or Cla I. Lane 1, $\lambda$ Hind III; 2, 009 Xba I; 3, 143 Xba I; 4, 012 Pst I; 5, 201 Pst I; 6, 157 Cla I; 7, 138 Cla I.

examined, primer OPA13 produced differences of two bands with isolate M348 and three bands with isolate 93M236 (Fig. 5). Four patterns were produced by primer HLWL85: isolates H78, 143, 349, 012 and H2ll showed one pattern; isolates L83 and M348 differed from each other and the other pattern by one band in each case; isolate 93M236 differed from the other isolates in at least six bands. When the sites of isolation of these fungi are considered, isolate M348 was from the skin of the scalp, isolate 93M236 was grown from fingernail and the six other isolates originated from skin or nail from the feet. The variations in the number of bands could indicate some genetic differences between the isolates, or perhaps the variety of $T$. mentagrophytes. The latter can be determined by mating tests with the telomorphs of $T$. mentagrophytes. Liu et al. [29] have demonstrated that this may be achieved by RAPD and differentiated $T$. mentagrophytes var. interdigitale from $T$. mentagrophytes var. mentagrophytes - although the patterns were very similar and differed by only one band.

Three of the primers screened had been applied to RAPD studies of other fungi. Primers ERIC 2 and ERIC IR were used for studies of C. albicans [30] and Malassezia species [13], but unfortunately these primers afforded no subspecies division of $T$. rubrum and only distinguished isolate 93M236 from the other T. mentagrophytes. Primer HLW85 was used to discriminate isolates from oral $C$. albicans infections [10], but failed to separate the $T$. rubrum isolates, although subtle differences were detected amongst $T$. mentagrophytes. However, all these primers permitted differentiation of the two dermatophyte species and concurred with the results of Liu et al. [31], who 


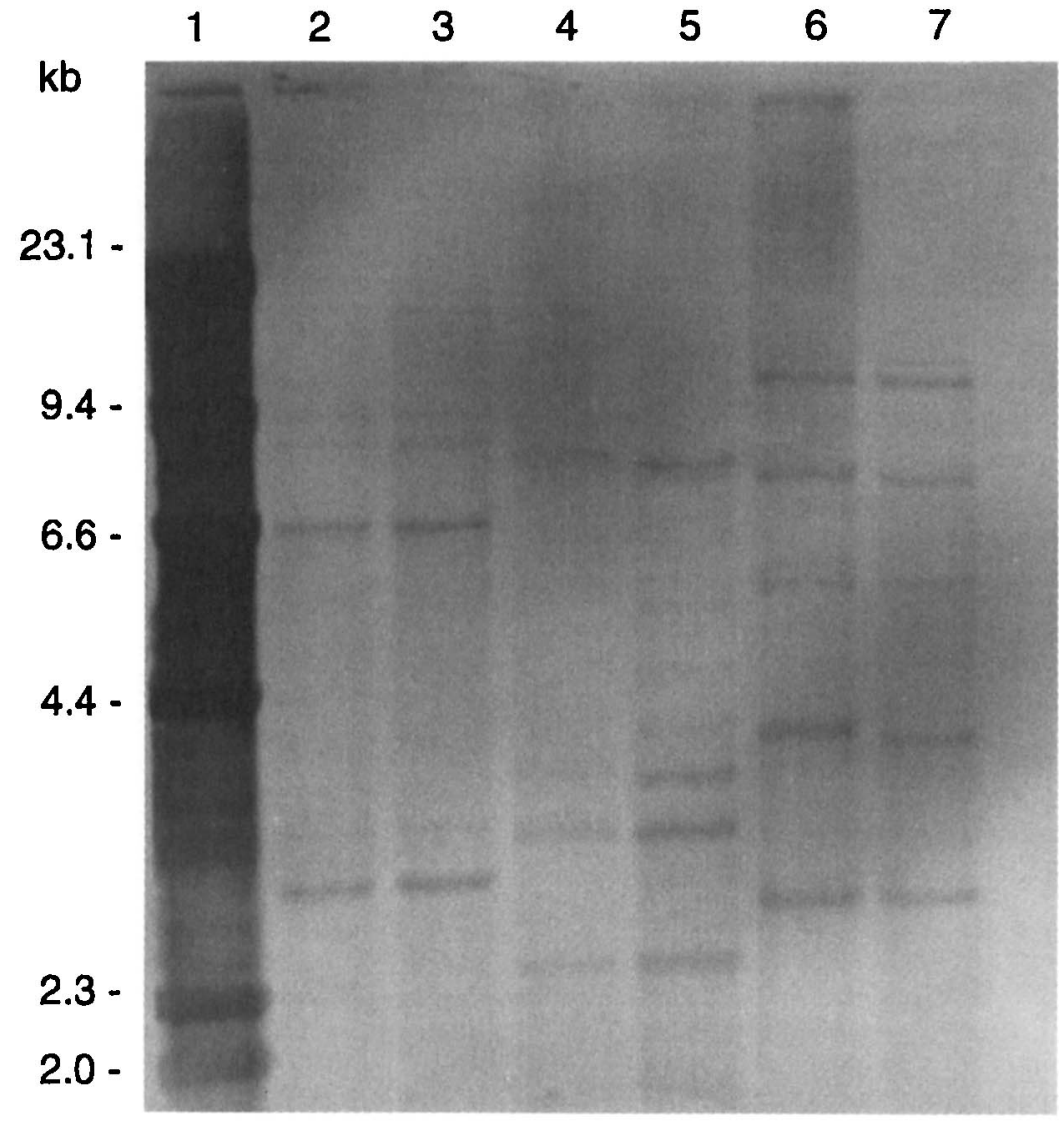

Fig. 4. Poly (dG-dT) blots of T. rubrum DNA digested with Xba I, Pst I or Cla I. Lane 1, $\lambda$ Hind III; 2, $108 X b a \mathrm{I} ; 3$, 038 XbaI; 4, 145 Pst I; 5, 171 Pst I; 6, 149 Cla I; 7, 93M161 Cla I.

differentiated the species $T$. mentagrophytes, T. rubrum and $T$. tonsurans with a 10 -mer oligonucleotide.

Recently, primers have been designed for the PCR detection of fungal DNA selecting a region of rDNA as the target [32]. Amplification of the 18S rDNA region followed by REA provided a method of speciating candidal yeasts [33]. A similar approach, this time analysing the $5.8 \mathrm{~S}$ and internal transcribed spacer (ITS) regions of the rDNA, separated a selection of basidiomycetous yeasts [34]. Comparisons of these DNA sequences revealed similarity between species in the $5.8 \mathrm{~S}$ gene, but indicated that there was some variation in the ITS regions. When the 5.8S gene and ITS regions were amplified from the rDNA of seven $T$. mentagrophytes and four $T$. rubrum isolates and digested with up to nine restriction endonucleases, only one isolate of $T$. mentagrophytes (93M236) could be distinguished although again the two species could be recognised easily (Table 1).

Variation in the intergenic spacer regions of rDNA has been reported between isolates of other fungi. For instance, part of an intergenic spacer region from the rDNA of Asp. nidulans was used as a probe against Eco RI-digested DNA from 11 isolates of Asp. fumigatus and three types were detected [35]. Poly- morphisms have been identified also in the spacer regions between the $16 \mathrm{~S}$ and $23 \mathrm{~S}$ rDNA of Cryptococcus neoformans isolates [36].

A number of molecular techniques have been applied to the differentiation of dermatophytes and most have indicated these to be a closely related group of fungi [3-5, 7, 37, 38]. Isolates of $T$. tonsurans were also examined by REA, poly(dG-dT), RAPD, REA of the 5.8S-ITS region (S. A. Howell and P. Johnson, data not shown) and these were found to be identical to each other and to resemble $T$. mentagrophytes, an observation described for comparisons of mitochondrial DNA patterns [7]. Other typing methods have been employed for dermatophyte epidemiology including polyacrylamide gel electrophoresis of whole-cell proteins from Microsporum canis [2]. This technique demonstrated inconsistent differences between clinical isolates which all resembled the (-) mating type of Arthroderma otae. However, mating studies of reference $(+)$ and $(-)$ type strains revealed that their progeny could be distinguished, showing that the PAGE technique was capable of distinguishing between genetically different forms.

All the techniques reported here successfully distinguish between the species $T$. mentagrophytes and $T$. rubrum and would provide rapid methods for recogni- 


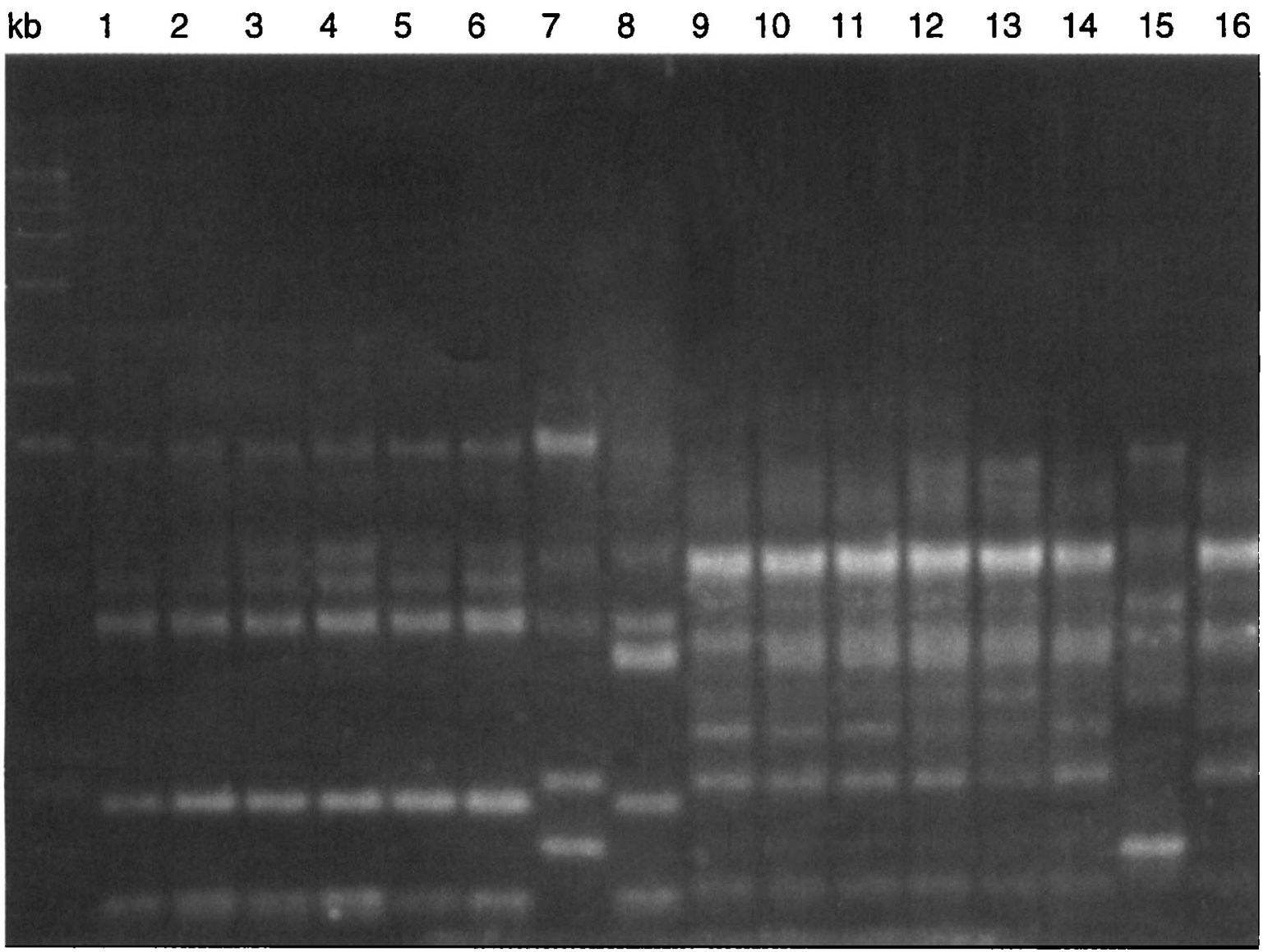

Fig. 5. RAPD screening of T. mentagrophytes isolates with primers OPA 13 and HLWL85. Isolates $93 \mathrm{M} 236$ and M348 were distinguished by OPA 13, and primer HLWL85 distinguished isolates L83, 93M236 and M348. Lane kb, 1-kb ladder. Samples amplified with primer OPA 13: lane 1, L83; 2, H78; 3, 143; 4, 012; 5, H211; 6, 349; 7, 93M236; 8, M348. Samples amplified with primer HLWL85: lane 9, L83; 10, H78; 11, 143; 12, 012; 13, H211; 14, 349; 15, 93M236; 16, M348.

Table 1. Taq I digestion of a PCR-amplified segment of rDNA from $T$. mentagrophytes and T. rubrum

\begin{tabular}{lclc}
\hline Species & Isolate no. & Isolation site & Approximate fragment size (bp) \\
\hline T. mentagrophytes & 12 & Nail & $310,260,90,80$ \\
& 143 & Skin, foot & $310,260,90,80$ \\
& 349 & Skin, foot & $310,260,90,80$ \\
& L83 & Nail, foot & $310,260,90,80$ \\
H78 & Nail, foot & $310,260,90,80$ \\
& 93M236 & Nail, finger & $300,270,90,80$ \\
& M348 & Skin, scalp & $310,260,90,80$ \\
& 244 & Skin, foot & $270,200,150,90,80$ \\
& 326 & Skin, foot & $270,200,150,90,80$ \\
& H396 & Nail, foot & $270,200,150,90,80$ \\
& AJ2 & Nail, foot & $270,200,150,90,80$ \\
\hline
\end{tabular}

tion of isolates reluctant to spore on laboratory media. However, further detailed study is required to find a suitable typing tool for the epidemiology of wild-type clinical dermatophyte isolates.

We are indebted to Sandoz Pharmaceuticals for support of this work and to the following for kindly providing strains: Dr Cefai, Department of Microbiology, Wrexham Maelor Hospital; Dr Clayton, Medical Mycology, St John's Institute of Dermatology, St Thomas' Hospital, London; Mr Johnson, Microbiology, Hammersmith Hospital, London; Dr Potts, Dermatology, Halifax General Hospital; Dr
Powell, Ogwr Health Unit, Princess of Wales Hospital, Bridgend; Dr Reuther, Microbiology, William Harvey Hospital, Ashford; Professor De Vroey, Mycology Unit, Department of Microbiology, Institute of Tropical Medicine, Antwerp, Belgium; Dr White, Department of Dermatology, Aberdeen Royal Infirmary.

\section{References}

1. Polonelli L, Castagnola M, Morace G. Identification and serotyping of Microsporum canis isolates by monoclonal antibodies. J Clin Microbiol 1986; 23: 609-615. 
2. Tucker WDL, Noble WC. The value of electrophoretic protein patterns for the study of Microsporum canis. J Med Vet Mycol 1990; 28: $117-123$.

3. Davison FD, Mackenzie DWR, Owen RJ. Deoxyribonucleic acid base compositions of dermatophytes. J Gen Microbiol 1980; 118: $465-470$.

4. Davison FD, Mackenzie DWR. DNA homology studies in the taxonomy of dermatophytes. Sabouraudia 1984; 22: 117-123.

5. Mochizuki T, Takada K, Watanabe S, Kawasaki M, Ishizaki H. Taxonomy of Trichophyton interdigitale (Trichophyton mentagrophytes var. interdigitale) by restriction enzyme analysis of mitochondrial DNA. J Med Vet Mycol 1990; 28: 191-196.

6. Mochizuki T, Watanabe S, Uehara M. Genetic homogeneity of Trichophyton mentagrophytes var. interdigitale isolated from geographically distant regions. J Med Vet Mycol 1996; 34: 139-143.

7. Nishio K, Kawasaki M, Ishizaki H. Phylogeny of the genera Trichophyton using mitochondrial DNA analysis. Mycopathologia 1992; 117: 127-132.

8. Bostock A, Khattak MN, Matthews R, Burnie J. Comparison of PCR fingerprinting, by random amplification of polymorphic DNA, with other molecular typing methods for Candida albicans. J Gen Microbiol 1993; 139: 2179-2184.

9. Hopfer RL, Walden P, Setterquist S, Highsmith WE. Detection and differentiation of fungi in clinical specimens using polymerase chain reaction (PCR) amplification and restriction enzyme analysis. $J$ Med Vet Mycol 1993; 31: 65-75.

10. Howell SA, Anthony RM, Power E. Application of RAPD and restriction enzyme analysis to the study of oral carriage of Candida albicans. Lett Appl Microbiol 1996; 22: 125-128.

11. Magee PT, Bowdin L, Staudinger J. Comparison of molecular typing methods for Candida albicans. J Clin Microbiol 1992; 30: $2674-2679$.

12. Anthony RM, Howell SA, Lloyd DH, Pinter L. Applications of DNA typing methods to the study of the epidemiology of Malassezia pachydermatis. Microb Ecol Health Dis 1994; 7 $161-168$.

13. van Belkum A, Boekhout $T$, Bosboom $R$. Monitoring spread of Malassezia infections in a neonatal intensive care unit by PCR-mediated genetic typing. J Clin Microbiol 1994; 32: $2528-2532$.

14. Loudon KW, Burnie JP, Coke AP, Matthews RC. Application of polymerase chain reaction to fingerprinting Aspergillus fumigatus by random amplification of polymorphic DNA. $J$ Clin Microbiol 1993; 31: 1117-1121.

15. Pitcher DG, Saunders NA, Owen RJ. Rapid extraction of bacterial genomic DNA with guanidium thiocyanate. Lett Appl Microbiol 1989; 8: 151-156.

16. Sambrook J. Fritsch EF, Maniatis T. Molecular cloning: laboratory manual, 2nd edn. Cold Spring Harbor, NY, Cold Spring Harbor Laboratory Press. 1989. 9.34-9.40.

17. Relman DA, Schmidt TM, MacDermott RP, Falkow S. Identification of the uncultured bacillus of Whipple's disease. $N$ Engl J Med 1992; 327: 293-301.

18. Wilson $\mathrm{KH}$, Blitchington RB, Greene RC. Amplification of bacterial $16 \mathrm{~S}$ ribosomal DNA with polymerase chain reaction. $J$ Clin Microbiol 1990; 28: 1942-1946.

19. Eden PA, Schmidt TM, Blakemore RP, Pace NR. Phylogenetic analysis of Aquaspirillum magnetotacitum using polymerase chain reaction-amplified $16 \mathrm{~S}$ rRNA-specific DNA. Int J Syst Bacteriol 1991; 41: 324-325.

20. Longhi S, Fusetti F, Grandori R, Lotti M, Vanoni $M$, Alberghina L. Cloning and nucleotide sequences of two lipase genes from Candida cylindracea. Biochim Biophys Acta 1992 1131: $227-232$.

21. Mazurier S, van der Giessen A, Heuvelman K, Wernars $K$ RAPD analysis of Campylobacter isolates: DNA fingerprinting without the need to purify DNA. Lett Appl Microbiol 1992; 14: $260-262$
22. White TJ, Bruns T, Lee S, Taylor J. Amplification and direct sequencing of fungal ribosomal RNA genes for phylogenetics. In: Innis MA, Gelfand DH, Sninsky JJ, White TJ (eds) PCR protocols. A guide to methods and applications. San Diego, CA, Academic Press. 1990. 315-322.

23. Wilkinson BM, Morris L, Adams DJ, Evans EGV, Lacey CJN, Walmsley RM. A new, sensitive polynucleotide probe for distinguishing Candida albicans strains and its use with a computer assisted archiving and pattern comparison system. $J$ Med Vet Mycol 1992; 30: 123-131.

24. Arif S, Barkham T, Power EG, Howell SA. Techniques for investigation of an apparent outbreak of infections with Candida glabrata. J Clin Microbiol 1996; 34: 2205-2209.

25. Hall LMC. Are point mutations or DNA rearrangements responsible for the restriction fragment length polymorphisms that are used to type bacteria? Microbiology 1994; 140: 197-204

26. Scherer S, Stevens DA. A Candida albicans dispersed, repeated gene family and its epidemiologic applications. Proc Natl Acad Sci USA 1988; 85: 1452-1456.

27. VanCouwenberghe CJ, Cohen SH, Tang YJ, Gumerlock $\mathrm{PH}$, Silva J. Genomic fingerprinting of epidemic and endemic strains of Stenotrophomonas maltophila (formerly Xanthomonas maltophila) by arbitrarily primed PCR. J Clin Microbiol 1995; 33: $1289-1291$.

28. Madico G, Akopyants NS, Berg DE. Arbitrarily primed PCR DNA fingerprinting of Escherichia coli $0157: \mathrm{H} 7$ strains by using templates from boiled cultures. J Clin Microbiol 1995; 33: $1534-1536$.

29. Liu D, Coloe S, Baird R, Pedersen J. PCR identification of Trichophyton mentagrophytes var. interdigitale and $T$. mentagrophytes var. mentagrophytes dermatophytes with a random primer. J Med Microbiol 1997; 46: 1043-1046.

30. van Belkum A, Mol W, van Saene R, Ball LM, van Velzen D, Quint W. PCR-mediated genotyping of Candida albicans strains from bone marrow transplant patients. Bone Marrow Transplant 1994; 13: $811-815$

31. Liu D, Coloe S, Pedersen J, Baird R. Use of arbitrarily primed polymerase chain reaction to differentiate Trichophyton dermatophytes. FEMS Microbiol Lett 1996; 136: 147-150.

32. Bock M, Maiwald M, Kappe R, Nickel P, Naher H. Polymerase chain reaction-based detection of dermatophyte DNA with a fungus-specific primer system. Mycoses 1994; 37: 79-84.

33. Maiwald M, Kappe R, Sonntag HG. Rapid presumptive identification of medically relevant yeasts to the species level by polymerase chain reaction and restriction enzyme analysis. $J$ Med Vet Mycol 1994; 32: 115-122.

34. Mitchell TG, White TJ, Taylor JW. Comparison of $5.8 \mathrm{~S}$ ribosomal DNA sequences among the basidiomycetous yeas genera Cystofilobasidium, Filobasidium and Filobasidiella. $J$ Med Vet Mycol 1992; 30: 207-218.

35. Spreadbury CL, Bainbridge BW, Cohen J. Restriction fragment length polymorphisms in isolates of Aspergillus fumigatus probed with part of the intergenic spacer region from the ribosomal RNA gene complex of Aspergillus nidulans. J Gen Microbiol 1990; 136: 1991-1994.

36. Fan M, Currie BP, Gutell RR, Ragan MA, Casadevall A. The 16S-like, $5.8 \mathrm{~S}$ and 23S-like rRNAs of the two varieties of Cryptococcus neoformans: sequence, secondary structure, phylogenetic analysis and restriction fragment polymorphisms. I Med Vet Mycol 1994; 32: 163-180.

37. de Bievre $C$, Dauguet $C$, Nguyen VH, Ibrahim-Granet $O$ Polymorphism in mitochondrial DNA of several Trichophyton rubrum isolates from clinical specimens. Ann Inst Pasteur/Microbiol 1987; 138: 719-727.

38. Leclerc MC, Philippe H, Gueho E. Phylogeny of dermatophytes and dimorphic fungi based on large subunit ribosomal RNA sequence comparisons. $J$ Med Vet Mycol 1994; 32: $331-341$ 